\title{
Learning Pharmacology in Mexico: A Survey of the Use and Views of Pharmacology Textbooks by Undergraduate Medical Students
}

\author{
Rosa Ventura-Martinez, Rebeca Aguirre-Hernandez, \\ Jacinto Santiago-Mejia, Claudia Gomez, Rodolfo Rodriguez \\ Department of Pharmacology, School of Medicine, National University of Mexico \\ Email: rventuram7@hotmail.com, rebeca.aguirrehdez@yahoo.com.mx. \\ samj@unam.mx,goac@unam.mx, rodcar@unam.mx
}

Received December $6^{\text {th }}, 2013$; revised January $6^{\text {th }}, 2014$; accepted January $13^{\text {th }}, 2014$

Copyright (C 2014 Rosa Ventura-Martinez et al. This is an open access article distributed under the Creative Commons Attribution License, which permits unrestricted use, distribution, and reproduction in any medium, provided the original work is properly cited. In accordance of the Creative Commons Attribution License all Copyrights (c) 2014 are reserved for SCIRP and the owner of the intellectual property Rosa Ventura-Martinez et al. All Copyright (C) 2014 are guarded by law and by SCIRP as a guardian.

Background: To date, little is known about the view of medical students towards pharmacology textbooks. This study aimed to investigate the preferences of second-year medical students towards pharmacology textbooks, and to identify the factors involved in book selection. Methods: Second-year medical students of the Medical School at the National University of Mexico (classes of 2010, 2011, and 2012) were asked to select their preferred textbook for studying pharmacology and preparing for exams from a list of nine textbooks. They also completed a 19-item questionnaire to identify and evaluate the reasons for their preferences. Results: A total of 1323 students completed the questionnaire, representing $45.59 \%$ of all medical students enrolled in 2010-2012. The two textbooks most preferred by students were Goodman \& Gilman (25.3\%) and Rodriguez et al. (27.3\%); preferences for the other books were Harvey \& Champe (13.9\%), Rang et al. (13.5\%), or Katzung et al. (12.3\%), and others (7.6\%). The usefulness and the adequacy of content were deemed equally important by students when choosing a textbook. Conclusions: Goodman \& Gilman, a well-known pharmacology textbook, and Rodriguez et al., a small-volume textbook, were preferred by these second-year medical students; their choices were based on relevant pharmacological information and adequacy of content.

Keywords: Pharmacology; Learning; Teaching; Textbooks; Medical Schools

\section{Introduction}

Academic success during the first 2 years of medical school generally depends on the ability of students to cope with a significantly more voluminous and demanding course load than previously experienced (Sawyer et al., 1996). This is true for all biomedical sciences, particularly pharmacology, a discipline with ever-increasing information. Basic pharmacology is a fundamental course that is usually taught in the second year in most medical schools, using traditional discipline-based or problembased learning curricula. Most medical schools mandate that a solid foundation in basic pharmacology is essential to understand and practice therapy, because drugs cannot be safely or rationally administered without a clear understanding of their site and mode of action, pharmacokinetics, side effects, interactions, and toxicity. However, learning and retention deficits of pharmacological information are major problems in undergraduate medical education, and these deficiencies are recognized worldwide (Ingenito et al., 1989; Dean et al., 2002; Rodriguez et al., 2002; Ling et al., 2008). Many studies have shown that many final-year medical students and new doctors are underprepared for effective and safe

\footnotetext{
"Corresponding author.
}

prescribing of drugs (Walley et al., 1994; Garbutt et al., 2005; Han et al., 2006; Maxwell et al., 2007; Harding et al., 2010), a view shared by many medical students (Heaton et al., 2008). It has been suggested that inadequate skill or knowledge of pharmacology contribute to prescribing faults (i.e., failure to decide which drug to use and how) and compromising patient safety (Dean et al., 2002; Harding et al., 2010; Otoom et al., 2006; Aronson, 2009; Gwee, 2009). Information overload, the proliferation of new drugs, recent curricular reforms, and inadequate teaching of medical pharmacology are the four main factors that contribute to the inadequate pharmacological education of medical students (Ingenito et al., 1989; Han et al., 2006; Heaton et al., 2008; Otoom et al., 2006; Achike et al., 2000).

To overcome these issues, a curriculum with a more selective content, coupled with a restricted list of drugs ("student formulary"), has been proposed and implemented in many medical schools (Orme et al., 2002; Maxwell et al., 2003; Rodriguez et al., 2009; Baker et al., 2011). We consider that the recent proposal of Ross and Maxwell is the most complete and useful approach for teaching and learning pharmacology in medical schools (Ross et al., 2012). However, the lack of appropriate textbook material is a major challenge for students who must 
cope with the traditional, oversized, pharmacology textbooks that grow larger with each new edition (Achike et al., 2000). In addition, most textbooks treat pharmacology as a basic science rather than a discipline that forms part of a medical curriculum; consequently, the clinical perspective may be lost in the vast quantity of basic pharmacological information. Most medical students dislike such textbooks. Faced with the ever-increasing breadth of pharmacology knowledge that they need to address, students (and medical educators) are confronted with the problem of how to extract the key information that is most relevant to their future clinical education.

To date, little is known about the view of medical students towards pharmacology textbooks. Therefore, the present research aimed to report on the development, reliability and validity of a questionnaire to investigate the preferences of second-year undergraduate medical students towards pharmacology textbooks. In addition to the planned validation studies, we determined the feasibility of using the same questionnaire to identify the factors that may influence their decisions when choosing a pharmacology textbook. The textbooks used to investigate students' view and preferences were chosen because all of them are recommended in our academic program, our medical library contains many copies of them, and because they vary considerably in terms of the amount of information being presented and the means of presenting this information. A total of 1323 second-year medical students of the Medical School at the National University of Mexico (classes of 2010, 2011, and 2012) participated in this study.

\section{Methods}

\section{Participants}

We enrolled 1360 medical students in the second year (448 in the class of 2010, 496 in the class of 2011, and 416 in the class of 2012) at the National University of Mexico Medical School, representing $45.59 \%$ of the total number of students (2983). Our school uses a traditional discipline-based curriculum in which pharmacology is a required course that is taught every year to approximately 950 undergraduate medical students divided into 32 groups of about 25 - 30 students each. The pharmacology course is taught in the second year alongside other discipline-based science courses, but before pathology and extensive clinical teaching. The course consists of two sessions lasting $2 \mathrm{~h}$ each per week on different weekdays. Although an active methodology is promoted, most sessions consist of $2 \mathrm{~h}$ lectures that are given by the same group of professors. The course also includes 30 laboratory sessions (mainly computer simulations) that last $4 \mathrm{~h}$ each. All groups begin and end the course on the same date.

\section{Textbooks Evaluated}

Nine pharmacology textbooks were chosen: "Pharmacology" (Harvey \& Champe, $4^{\text {th }} / 5^{\text {th }}$ editions, 2008-2011, USA), "Principles of Pharmacology: The Pathophysiologic Basis of Drug Therapy" (Golan et al., $2^{\text {nd }} / 3^{\text {rd }}$ editions, 2007-2011, USA), "Goodman \& Gilman's The Pharmacological Basis of Therapeutics” (Brunton et al., 11 $12^{\text {th }} / 1{ }^{\text {th }}$ editions, 2006-2011, USA), "Basic and Clinical Pharmacology" (Katzung et al., 11 $11^{\text {th }} / 12^{\text {th }}$ editions, 2009-2011, USA), "Pharmacology" (Rang et al., $6^{\text {th }} / 7^{\text {th }}$ editions, 2007-2011, UK), “Levine's Pharmacology, Actions and Reactions" (Walsh et al., $7^{\text {th }}$ edition, 2005, UK), "Velazquez Basic and Clinical Pharmacology" (Lorenzo-Fer- nandez, $17^{\text {th }} / 18^{\text {th }}$ editions, 2004-2009, Spain), "Medical Pharmacology" (Mendoza, $1^{\text {st }}$ edition, 2008, Mexico), and "Pharmacology and Therapeutics Guide" (Rodriguez et al., $2^{\text {nd }}$ edition, 2009, Mexico). These textbooks were chosen because they are listed in our academic program and our medical library contains many copies of these textbooks (Spanish version).

\section{Development of the Questionnaire}

We determined that the questionnaire should focus on the students' perceptions of pharmacology textbooks. Therefore, we developed a questionnaire that included items derived from informal conversations with and complaints from medical students about the pharmacology textbooks they had used throughout the year.

The initial questionnaire included 20 items that were designed to investigate the students' textbook preferences and to gain some insight into the reasons for their preferences, as well as items designed to evaluate the usefulness and adequacy of the preferred textbook. In May 2009, we conducted a pilot study of 416 medical students to evaluate the comprehensibility and relevance of the questions, and several changes were made based on their feedback. We also tried to improve the comprehensibility and clarity of each item. The questionnaire took < 10 min to complete.

The final version of the questionnaire was two pages long, and consisted of 20 questions (Table 1). The questionnaire first asked students to select the pharmacology textbook that they used during the year to study and prepare for examinations, as well as how often they used it. Next, the students completed 19 items that explored the reasons for their preference. The students were asked to indicate how much they agreed with each statement using a 5-point Likert scale ( $1=$ never; 2 = sometimes; 3 = frequently; 4 = almost always; 5 = always). To help the students identify the textbook, we provided them with a colour page containing images of the pharmacology textbooks in alphabetical order. Participation was voluntary and anonymous, answers were manually reviewed, and data were entered into a database for statistical analysis.

At the end of the questionnaire, students were asked to state their overall textbook preferences (encyclopaedic vs. concise) for studying basic medical sciences. The surveys were conducted in May 2010, 2011, and 2012, coinciding with the end of each academic year.

Ethical statement

All of the participants were informed about the aim of the study and the content of the questionnaire. The questionnaire was anonymous and did not request any information that could reveal the identity of the respondents. The students voluntarily participated in the survey. They were free to leave any questions or the whole questionnaire unanswered if they wished to do so. Studies in which only questionnaires are applied or interviews are made are classified, by the General Health Law for Health Research of Mexico, as research studies in which the population is not put at any risk (General Health Law Regulations with regard to Research on the Health Sciences, Mexico). It also states that in this type of studies, the Ethical Committee can exempt the researchers from requesting the informed consent.

\section{Data Analysis}

We calculated percentages to summarize the information of 
Table 1.

Questionnaire given to second-year medical students regarding pharmacology textbooks.

INSTRUCTIONS: First, select from the attached page the pharmacology textbook that you preferred during the year when preparing for your coursework or examinations; then, answer the following questions.

1) How often did you use it?

2) Does it describe the fundamentals of pharmacology?

3) Does it explain the pharmacodynamics and pharmacokinetics of major drugs in a comprehensive manner?

4) Does it identify drugs that are more frequently used (prototypes) in general medicine?

5) Does it describe the physiopathology of major diseases and explain its importance in drug selection?

6) Does it provide detailed descriptions of the pharmacology of drugs as a basis for their clinical use?

7) Does it refer to pharmacological topics that are only useful for second-year medical students?

8) Does it stimulate your interest in the topic and motivate you to learn on your own?

9) Does it encourage the integration of pharmacology with other disciplines in the curriculum?

10) Does it stimulate your interest in more common diseases?

11) Is the material well organized?

12) Does the sequence of themes facilitate comprehension of the entire discipline?

13) Is the information presented smoothly and does it help to integrate your knowledge?

14) Are the contents clear and concise?

15) Was the writing easily understood and did chapter length favour learning?

16) Was it necessary to consult another textbook to achieve your learning objectives?

17) Does it prompt you to consult useful literature in this field?

18) Does it offer an opportunity for self-evaluation?

19) Would you recommend this textbook to other students?

20) Does the textbook cover all of the scheduled topics in the curriculum?

nominal and ordinal variables. Exploratory factor analysis (Tabachnick et al., 2007) was applied to each student population and to the whole sample in order to determine if the correlation between the questions could be explained by a few latent variables. Additive scales were calculated based on the results of the factor model. A multinomial logistic regression model (Hosmer et al., 2000) was fitted to predict the book preferred by the students using as independent variables the additive scales and the school class. Statistical analyses were done with R Core Team 2012 version 2.15.1 (R Core Team) and SPSS for Windows Statistic Package (version 20). A P value of $<0.05$ was considered significant.

\section{Results}

\section{Summary Statistics}

The questionnaire was fully answered by 1323 medical students (97.3\%); thirty-seven incomplete questionnaires were excluded from the analysis. In the whole population, the mean age was 19.3 (range 17 - 41) years; 63.1\% were female and $36.9 \%$ were male.

About $50 \%$ of the 1323 surveyed students preferred the books by either Goodman \& Gilman or Rodriguez et al. (Table 2). Nearly $40 \%$ of the students preferred the textbooks by Harvey and Champe, Rang et al. or Katzung et al., and less than $10 \%$ of the students used another textbook. The percentage of students that used the book by Katzung et al. increased 7.5\% between the first and the last academic years reported in Table 2. Also, in this time period, the percentage of students that favored the book by Rodriguez et al. increased 5\% while $8.4 \%$ less students chose the book by Goodman \& Gilman.

\section{Questionnaire’s Latent Variables}

More than $90 \%$ of the answers to the 19 items comprising the second part of the questionnaire were concentrated in just three categories: "frequently”, “almost always” and "always”. Question 16 regarding the need to look up another pharmacology textbook in order to achieve the study objectives had a different response pattern and was ignored in subsequent analysis. The polychoric correlation coefficient (Mislewy, 1986) was used to measure the association between items and to do an exploratory factor analysis. The correlation matrices of the three studied populations were similar to each other. Thus we decided to work with a single data set that contained information of 1323 students from the three academic years instead of doing a separate analysis for each of them.

Based on several criterions (Tabachnick et al., 2007) and preliminary analyses we decided to extract 4 factors. We examined the rotated and unrotated solutions, the percentage of variance explained and the communality values. The model was re-fitted using weighted least squares and omitting questions 17 and 18 because their communality values were around 0.35 . The factor loadings shown in Table 3 were obtained after applying a quartimin rotation. This model explained $66 \%$ of the total variance of the sixteen questions. The correlation between the four extracted factors ranged between 0.56 and 0.74 . The elements of the residual matrix ranged between -0.03 and 0.49 . Cronbach's alpha was 0.838 for Factor 1, 0.859 for Factor 2, 0.788 for Factor 3 and 0.776 for Factor 4 . Factor loadings greater than 0.31 were considered as significantly different from zero. We interpreted the factors as follows: Factor 1, pertinent pharmacological information; Factor 2, appropriate information presentation; Factor 3, meaningful medical context; and Factor 4, adequacy of content.

\section{Characteristics of the Chosen Book}

Additive scales were calculated by adding the codes (never $=$ 1 , sometimes $=2$, frequently $=3$, almost always $=4$, always $=$ 5) assigned to the categories of the variables that loaded heavily 
Table 2.

Number of undergraduate medical students that studied pharmacology in their second year and the percentages of students that preferred each textbook.

\begin{tabular}{ccccccccc}
\hline Academic year & $\boldsymbol{N}$ & $\begin{array}{c}\text { Harvey \& } \\
\text { Champe }\end{array}$ & $\begin{array}{c}\text { Goodman \& Gil- } \\
\text { man }\end{array}$ & Katzung et al. & Rang et al. & Rodriguez et al. & Others & Total \\
\hline $2009-2010$ & 448 & 14.5 & 27.9 & 8.0 & 16.3 & 24.8 & 8.5 & 100 \\
$2010-2011$ & 476 & 12.2 & 27.7 & 13.7 & 13.4 & 27.5 & 5.5 & 100 \\
$2011-2012$ & 399 & 15.3 & 19.5 & 15.5 & 10.5 & 29.8 & 9.3 & 100 \\
Overall & 1323 & 13.9 & 25.3 & 12.3 & 13.5 & 27.3 & 7.6 & 100 \\
\hline
\end{tabular}

Table 3.

Factor loading and communalities for the four factors.

\begin{tabular}{|c|c|c|c|c|c|}
\hline \multirow[b]{2}{*}{ Item } & \multicolumn{5}{|c|}{ Factor } \\
\hline & F1 & F2 & F3 & F4 & Communality \\
\hline
\end{tabular}

Factor 1: Pertinent pharmacological information

3) Does it explain the pharmacodynamics and pharmacokinetics

of major drugs in a comprehensive manner?

tics

2) Does it describe the fundamentals of pharmacology?

$\begin{array}{rrrrrr}\mathbf{0 . 8 0} & -0.11 & -0.04 & 0.13 & 0.63 \\ & \mathbf{0 . 7 3} & 0.03 & -0.03 & 0.09 & 0.61 \\ & \mathbf{0 . 6 8} & 0.06 & 0.15 & -0.03 & 0.67 \\ \mathbf{0 . 5 3} & 0.28 & 0.20 & -0.14 & 0.62\end{array}$

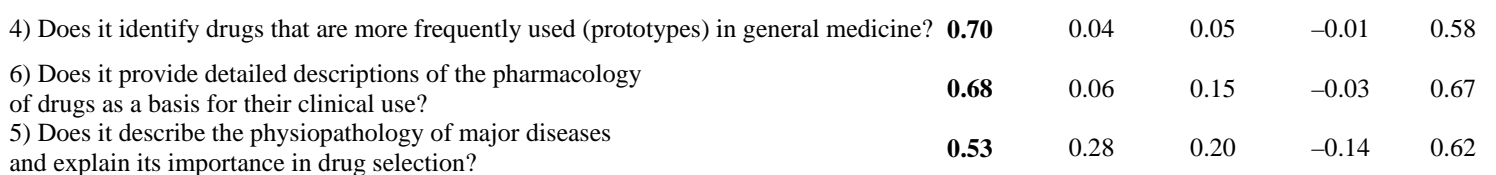

and explain its importance in drug selection?

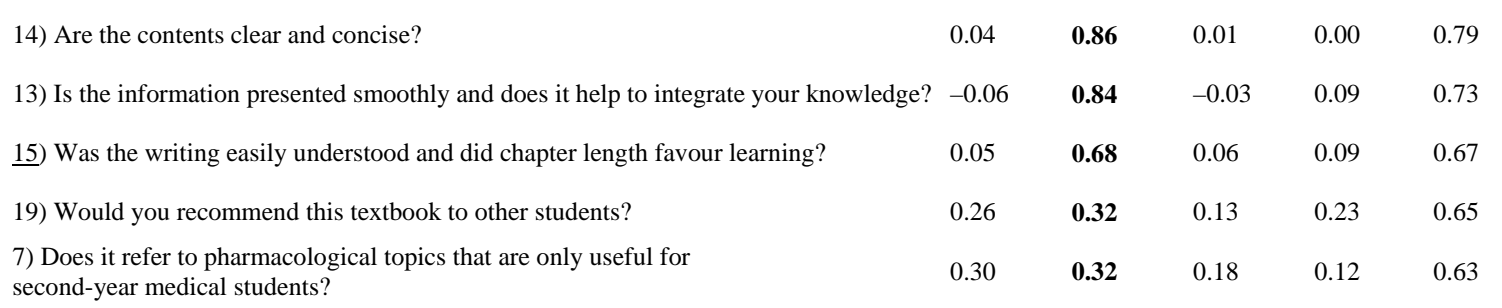

Factor 3: Meaningful medical context

9) Does it encourage the integration of pharmacology with other disciplines in the cur- 0.01 riculum?

10) Does it stimulate your interest in more common diseases?

0.00

$\begin{array}{llll}-0.10 & \mathbf{0 . 8 5} & 0.08 & 0.73 \\ 0.06 & \mathbf{0 . 7 6} & -0.01 & 0.62 \\ 0.19 & \mathbf{0 . 5 3} & 0.00 & 0.60\end{array}$

8) Does it stimulate your interest in the topic and motivate you to learn on your own?

0.14

\section{Factor 4: Adequacy of content}

12) Does the sequence of themes facilitate comprehension of the entire discipline?

$\begin{array}{lllll}-0.04 & 0.13 & 0.13 & \mathbf{0 . 7 2} & 0.76 \\ 0.14 & 0.03 & -0.01 & \mathbf{0 . 7 2} & 0.69 \\ 0.15 & 0.13 & 0.12 & \mathbf{0 . 4 2} & 0.51\end{array}$

11) Is the material well organized?

20) Does it cover all of the scheduled topics in the curriculum?

The model was fitted using the weighted least squares method and quartimin rotation. Loading values $>0.31$ were considered significant.

on each factor. A multinomial logistic regression model was fitted to determine if the additive scales and the school class predicted the book preferred by the students. In this analysis, the books were classified into four categories: 1, Goodman and Gilman; 2, Rodriguez et al.; 3, Harvey and Champe, and Rang et al.; and 4, Katzung et al, and "Others". Only additive scales 1,2 , and 4 were significantly associated with the student's book preferences (Table 4). An increment in the value of the second additive scale (appropriate information presentation) increased the odds of preferring any book instead of Goodman and Gilman. However, an increment in the first and fourth additive scales (pertinent pharmacological information and adequacy of content respectively) reduced the odds of preferring any book as compared to that written by Goodman and Gilman

Among 2010 students, the odds of preferring the book of Rodriguez et al. was significantly smaller than the odds of Goodman and Gilman $(\mathrm{P}=0.028)$. No significant differences were found between the textbook preferred by cohorts 2011 and 
Multinomial logistic regression model fitted to predict the book preferred by the students ${ }^{1}$.

\begin{tabular}{|c|c|c|c|c|c|c|c|}
\hline \multirow{2}{*}{ Book } & \multirow{2}{*}{ Variable } & \multirow{2}{*}{ Coefficient } & \multirow{2}{*}{$\begin{array}{l}\text { Stand. } \\
\text { Error }\end{array}$} & \multirow{2}{*}{$\mathbf{P}$} & \multirow{2}{*}{ OR } & \multicolumn{2}{|c|}{$95 \%$ confidence interval } \\
\hline & & & & & & Lower limit & Upper limit \\
\hline \multirow[t]{6}{*}{ Rodriguez et al. } & Constant & 0.51 & 0.64 & 0.426 & & & \\
\hline & class 2010 & -0.46 & 0.21 & 0.028 & 0.63 & 0.42 & 0.95 \\
\hline & class 2011 & -0.29 & 0.21 & 0.165 & 0.75 & 0.50 & 1.12 \\
\hline & additive scale 1 & -0.39 & 0.04 & 0.000 & 0.68 & 0.63 & 0.73 \\
\hline & additive scale 2 & 0.46 & 0.04 & 0.000 & 1.59 & 1.46 & 1.72 \\
\hline & additive scale 4 & -0.12 & 0.06 & 0.045 & 0.88 & 0.78 & 1.00 \\
\hline \multirow[t]{6}{*}{ Harvey and Champe; Rang et al. } & Constant & 0.46 & 0.63 & 0.459 & & & \\
\hline & class 2010 & -0.09 & 0.21 & 0.669 & 0.92 & 0.61 & 1.37 \\
\hline & class 2011 & -0.21 & 0.21 & 0.320 & 0.81 & 0.54 & 1.22 \\
\hline & additive scale 1 & -0.32 & 0.04 & 0.000 & 0.72 & 0.67 & 0.78 \\
\hline & additive scale 2 & 0.44 & 0.04 & 0.000 & 1.55 & 1.43 & 1.68 \\
\hline & additive scale 4 & -0.20 & 0.06 & 0.001 & 0.82 & 0.73 & 0.92 \\
\hline \multirow[t]{6}{*}{$\begin{array}{l}\text { Katzung et al.; } \\
\text { "Others" }\end{array}$} & Constant & 1.98 & 0.62 & 0.001 & & & \\
\hline & class 2010 & -0.72 & 0.22 & 0.001 & 0.48 & 0.32 & 0.74 \\
\hline & class 2011 & -0.52 & 0.21 & 0.014 & 0.59 & 0.39 & 0.90 \\
\hline & additive scale 1 & -0.27 & 0.04 & 0.000 & 0.76 & 0.71 & 0.83 \\
\hline & additive scale 2 & 0.28 & 0.04 & 0.000 & 1.32 & 1.22 & 1.43 \\
\hline & additive scale 4 & -0.13 & 0.06 & 0.028 & 0.88 & 0.78 & 0.99 \\
\hline
\end{tabular}

${ }^{1}$ The reference category for the dependent variable was the book by Goodman and Gilman; therefore, its odds ratios were 1 . The reference category for the school class was 2012. The additive scales are interpreted as follows: 1) pertinent pharmacological information, 2) appropriate information presentation, 4) adequacy of content. OR means odds ratio.

2012 ( $\mathrm{P}=0.165$ ), Table 4. The odds of choosing either Harvey and Champe or Rang et al instead of Goodman and Gilman did not depend on the class to which the students belonged $(\mathrm{P}=$ 0.669 for class 2010 against 2012 and $\mathrm{P}=0.320$ for class 2011 compared to 2012). Significant differences were found between class 2012 and the other two with regard to the odds of choosing between Katzung et al or the "Others" and Goodman and Gilman ( $\mathrm{P}=0.001$ for class 2010 versus 2012; $\mathrm{P}=0.014$ for class 2011 compared to 2012).

Finally, almost three-quarters (72\%) of the students expressed their overall preferences for small-size, concise books over lengthy, more complete textbooks.

\section{Discussion}

Despite the importance of Internet sources to provide information on health sciences, printed textbooks have long been central to medical curricula and continue to play a valuable role in medical education. Pharmacology is not an exception, and textbooks are the main resource for medical students in search of knowledge, as opposed to information, on drugs. However, the most widely recommended pharmacology textbooks are voluminous, containing copious information (Achike et al., 2000) that far exceeds the core knowledge recommended for undergraduate medical students (Orme et al., 2002; Rodriguez et al., 2009; Dornhorst, 1981; Klatt et al., 2011). Many medical students dislike this type of textbook, and frequently complain about their length and complexity.

In the present study, the textbooks by Goodman \& Gilman and Rodriguez et al. were the two most preferred pharmacology textbooks among second-year medical students for studying and preparing for their exams. Our finding that Goodman \& Gilman was one of the two most preferred textbooks is not surprising. Since its first publication in 1941, this textbook has become accepted as the most important textbook in its class, and as one of the most complete guides for teaching and learning pharmacology. However, as the extent of pharmacology knowledge grows, the content of the textbook increases with each new edition, continuing to include details pertinent to the discipline but that may be of limited relevance to undergraduate medical students.

The high preference among these medical students for Rodriguez et al. is also notable. There are many differences between Goodman \& Gilman and Rodriguez et al. For example, Goodman \& Gilman is an accredited pharmacology reference source that is useful for all types of students and health professionals interested in pharmacology, whereas Rodriguez et al. is 
a small-volume text that is designed to confront the changes that are taking place in the medical curriculum (Chiu-Yin, 2002; Faingold et al., 2002), and to limit information overload. Rather than including a range of issues of basic pharmacology, it focuses on core pharmacology knowledge, referring only to the general concepts and principles of the discipline that are important for medical students. It also includes a careful summary of essential drug information that all medical students should master before graduation, which is complemented by a core list of commonly prescribed drugs consistent with British Pharmacology Society recommendations (Maxwell et al., 2003).

It can be inferred that Goodman \& Gilman was preferred because of its encyclopaedic content, while the preference for Rodriguez et al. probably reflects the pragmatism of some students who prefer more concrete, medically relevant information. The marked differences in content between these two textbooks are particularly clear in terms of how they deal with individual topics and the entire discipline. For example, Goodman \& Gilman assigns 115 pages to pharmacokinetics, whereas Rodriguez et al. assign 30 pages to the same theme. The $12^{\text {th }}$ edition of Goodman \& Gilman is $>1800$ pages long, indexes over 1250 generic drugs (some of them without real clinical use), and weighs over $3.8 \mathrm{~kg}$. In contrast, the $2^{\text {nd }}$ edition of Rodriguez et al. is $<400$ pages long, indexes $<440$ chemical entities, and weighs $<800$ g. Rodriguez et al. focuses on what medical students need to study and at what depth. This textbook gives priority to 160 representative, clinically important classes of drugs (therapeutic prototypes) that medical students are expected to know in detail, including the name and drug class, mechanism of action, evidence-based clinical indications, important contraindications, most frequent and severe adverse reactions, clinically significant interactions, and possible substitutes. This textbook focuses on drugs that are commonly prescribed in primary and secondary care. Interestingly, 47 of the 100 drugs that are most commonly used in primary and secondary care settings in the UK (Baker et al., 2011) are mentioned in Rodriguez et al. Of the remaining 53, 28 are considered to be complementary drugs and 25 are not listed in Rodriguez et al. Differences in the numbers of drugs and the importance given to each drug between the core list in the UK and the list included in Rodriguez et al. can be explained by differences in healthcare between Mexico and Europe (Rodriguez et al., 2009).

We found that between 2010 and 2012, the percentage of students that preferred Rodriguez et al. increased by $5 \%$ while the percentage of students that preferred Goodman \& Gilman decreased by $8.4 \%$. We also found that other well-known textbooks (Harvey \& Champe, Rang et al, and Katzung et al.) were preferred by fewer students than expected, but the preference for Katzung et al. increased by 7.5\% from 2010 to 2012 .

The pharmacology textbooks evaluated in the present study vary considerably in terms of the amount of information being presented and the means of presenting this information. The students rated each factor listed in the questionnaire for their preferred textbook. The wide variations in responses suggest that students are discerning consumers of textbooks. The usefulness and the adequacy of content were deemed equally important by students when choosing a textbook. Factor analysis grouped the reasons that influenced the preference of students for a given textbook into 4 clusters: 1) pertinence of pharmacological information (e.g., the textbook explains the pharmacodynamic and pharmacokinetic properties of the major drugs in a comprehensive manner, and identifies drugs that are commonly used in general medicine); 2) appropriate information presentation (e.g., the textbook content is clear and concise, and the information is smoothly presented and helps to integrate knowledge); 3) meaningful medical context (e.g., the textbook encourages integration of pharmacology knowledge with that of other medical disciplines, and focuses on the more common diseases); and 4) adequacy of content (e.g., the sequence of themes facilitates comprehension of the entire discipline, and the material is well-organized). Cronbach's $\alpha$ coefficients indicated good internal consistency among the items included in each of the four factors $(0.838,0.859,0.788$, and 0.776 , respectively). Overall, these findings indicate that we developed a valid and reliable questionnaire.

Intriguingly, the preference for Goodman \& Gilman in our student population decreased between 2010 and 2012, whereas Rodriguez et al. and Katzung et al. gained popularity during this time. From a student's perspective, Goodman \& Gilman has adequate content and pertinent pharmacological information but fails to present the information appropriately. Regarding the other textbooks included in our survey, the preference for Rang et al. decreased slightly, while the preference for Harvey \& Champe or the other textbooks was largely unchanged over the 3 years.

Finally, most of the students (72\%) reported their overall preference for concise medical textbooks. This confirms the view of some authors who think that, in medical education, bulky textbooks are suitable as reference textbooks but not for regular reading (Achike et al., 2000).

In medicine, students and faculty members rely on textbooks for guidance and learning. We believe that this educational resource should be evaluated first, when trying to improve pharmacology education in medical schools. We also propose that the pharmacology textbooks recommended to undergraduate medical students are medically oriented and of a manageable and appropriate length with respect to the topics covered in the textbook.

To our knowledge, this is the first study to provide comprehensive data on the reading preferences of medical students in relation to pharmacology, and the reasons for preferring a specific pharmacology textbook. We believe that our results will assist authors to facilitate pharmacology learning by producing textbooks that suit different styles of learning (Gurpinar et al., 2011; Shukr et al., 2013).

Three important limitations of our study must be considered when interpreting our results. First, our study was conducted at one medical school in one country. Therefore, the results cannot be extrapolated to medical students at other medical schools. Second, the scope of our study was limited in that we only included nine of more than two dozen pharmacology widely available textbooks. Three, we surveyed young medical students with relatively limited medical knowledge and skills. Thus, our findings need to be confirmed in other studies.

\section{Conclusions}

Pharmacology textbooks vary in terms of the amount of information being presented as well as the means of presenting the information. Goodman \& Gilman, a well-known treatise of pharmacology, and Rodriguez et al., a small, concise textbook of pharmacology, were the preferred pharmacology textbooks among these second-year undergraduate medical students. Other well-known textbooks were used less frequently than expected. Medical students have different educational abilities and may 
benefit from the availability of different types of textbooks because it enables them to choose a textbook that fulfils their information needs and reading skills. As long as students are the centre of medical education, these results suggest that textbook authors should carefully consider the views and preferences of students. The next step is to test whether the use of these textbooks influences the learning and retention of pharmacological knowledge among medical students.

\section{Competing Interests}

The authors declare that they have no competing interests.

\section{Acknowledgements}

The authors thank the students from the Faculty of Medicine of the National University of Mexico who participated in the study. In addition, we appreciate the editorial assistance from Stallard Scientific Editing.

\section{REFERENCES}

Achike, F. I., \& Ogle, C. W. (2000). Information overload in the teaching of pharmacology. Journal of Clinical Pharmacology, 40, 177-183. http://dx.doi.org/10.1177/00912700022008838

Aronson, J. K. (2009). Medication errors: Emerging solutions. British Journal of Clinical Pharmacology, 67, 589-591. http://dx.doi.org/10.1111/j.1365-2125.2009.03420.x

Baker, E., Roberts, A. P., Wilde, K., Walton, H., Suri, S., Rull, G., \& Webb, A. (2011). Development of a core drug list towards improving prescribing education and reducing errors in the UK. British Journal of Clinical Pharmacology, 71, 190-198.

http://dx.doi.org/10.1111/j.1365-2125.2010.03823.x

Chiu-Yin, K. (2002). Problem-based learning and teaching of medical pharmacology. Naunyn Schmiedebergs Archives of Pharmacology, 366, 10-17. http://dx.doi.org/10.1007/s00210-002-0561-y

Dean, B., Schachter, M., Vincent, C., \& Barber, N. (2002). Prescribing errors in hospital inpatients: Their incidence and clinical significance. Quality \& Safety Health, 11, 340-344.

http://dx.doi.org/10.1136/qhc.11.4.340

Dornhorst, A. C. (1981). Information overload: Why medical education needs a shake-up. Lancet, 2, 513-514. http://dx.doi.org/10.1016/S0140-6736(81)90894-1

Faingold, C. L., \& Dunaway, G. A. (2002). Teaching pharmacology within a multidisciplinary organ system-based medical curriculum. Naunyn Schmiedebergs Archives of Pharmacology, 366, 18-25. http://dx.doi.org/10.1007/s00210-002-0565-7

Garbutt, J. M., Highstein, G., Jeffe, D. B., Dunagan, W. C., \& Frasier, V. J. (2005). Safe medication prescribing: Training and experience of medical students and house staff at a large teaching hospital. Academic Medicine, 80, 594-599. http://dx.doi.org/10.1097/00001888-200506000-00015

Gurpinar, E., Bati, H., \& Tetik, C. (2011). Learning styles of medical students change in relation to time. Advances in Physiology Education, 35, 307-311. http://dx.doi.org/10.1152/advan.00047.2011

Gwee, M. C. E. (2009). Teaching medical pharmacology: The need to nurture the early development of desired attitudes for safe and rational drug prescribing. Medical Teacher, 31, 847-854. http://dx.doi.org/10.1080/01421590903168119

Han, W. H., \& Maxwell, S. R. J. (2006). Are medical students adequately trained to prescribe at the point of graduation? Views of first year foundation doctors. Scottish Medical Journal, 51, 27-32. http://dx.doi.org/10.1258/rsmsmj.51.4.27

Harding, S., Britten, N., \& Bristow, D. (2010). The performance of junior doctors in applying clinical pharmacology knowledge and prescribing skills to standardized clinical cases. British Journal of Clinical Pharmacology, 69, 598-606.

http://dx.doi.org/10.1111/j.1365-2125.2010.03645.x
Heaton, A., Webb, D. J., \& Maxwell, S. R. J. (2008). Undergraduate preparation for prescribing: The views of 2412 UK medical students and recent graduates. British Journal of Clinical Pharmacology, 66, 128-134. http://dx.doi.org/10.1111/j.1365-2125.2008.03197.x

Hosmer, D. W., \& Lemeshow, S. (2000). Applied logistic regression. New York: Wiley-Interscience. http://dx.doi.org/10.1002/0471722146

Ingenito, A. J., Lathers, C. M., \& Burford, H. J. (1989). Instruction in clinical pharmacology: Changes in the wind. Journal of Clinical Pharmacology, 29, 7-17.

http://dx.doi.org/10.1002/j.1552-4604.1989.tb03231.x

Klatt, E. C., \& Klatt, C. A. (2011). How much is too much reading for medical students? Assigned reading and reading rates at one medical school. Academic Medicine, 86, 1079-1083. http://dx.doi.org/10.1002/j.1552-4604.1989.tb03231.x

Ling, Y., Swanson, D. B., Holtzman, K., \& Bucak, S. D. (2008). Retention of basic science information by senior medical students. Academic Medicine, 83, S82-S85. http://dx.doi.org/10.1097/ACM.0b013e318183e2fc

Maxwell, S. R. J., \& Walley, T. (2003). Teaching safe and effective prescribing in UK medical schools: A core curriculum for tomorrow's doctors. British Journal of Clinical Pharmacology, 55, 496503. http://dx.doi.org/10.1046/j.1365-2125.2003.01878.x

Maxwell, S. R. J., Cascorbi, I., Orme, M., \& Webb, D. (2007). Educating European (junior) doctors for safe prescribing. Basic \& Clinical Pharmacology \& Toxicology, 101, 395-400. http://dx.doi.org/10.1111/j.1742-7843.2007.00141.x

Mislevy, R. J. (1986). Recent developments in the factor analysis of categorical data. Journal of Educational Statistics, 11, 3-31. http://dx.doi.org/10.2307/1164846

Orme, M., Frolich, J., \& Vrhovac, B. (2002). Towards a core curriculum in clinical pharmacology for undergraduate medical students. European Journal of Clinical Pharmacology, 58, 635-640. http://dx.doi.org/10.1007/s00228-002-0531-9

Otoom, A. S., \& Sequeira, R. P. (2006). Health care providers' perceptions of the problems and causes of irrational use of drugs in two Middle East countries. International Journal of Clinical Practice, 60, 565-570. http://dx.doi.org/10.1111/j.1742-1241.2005.00808.x

$\mathrm{R}$ Core Team. A language and environment for statistical computing. $\mathrm{R}$ Foundation for Statistical Computing. http://www.R-project.org

General Health Law Regulations with regard to Research on the Health Sciences, Mexico. http://www.salud.gob.mx/unidades/cdi/nom/compi/rlgsmis.html

Rodriguez, R., Campos-Sepulveda, E., Vidrio, H., Contreras, E., \& Valenzuela, F. (2002). Evaluating knowledge retention of third-year medical students taught with an innovative pharmacology program. Academic Medicine, 77, 574-577.

http://dx.doi.org/10.1097/00001888-200206000-00018

Rodriguez, R., Vidrio, H., \& Campos, E. (2009). Medicalization of pharmacology teaching: An urgent need in the medical curriculum. Proccedings of the Western Pharmacology Society, New York, NY: Curran Associates, 120-128.

Ross, S., \& Maxwell, S. (2012). Prescribing and the curriculum for tomorrow's doctors: BPS curriculum in clinical pharmacology and prescribing for medical students. British Journal of Clinical Pharmacology, 74, 644-661.

http://dx.doi.org/10.1097/00001888-200206000-00018

Sawyer, S. J., Sylvestre, P. B., Girard, R. A., \& Snow, M. H. (1996). Effects of supplemental instruction on mean test scores and failure rates in medical school courses. Academic Medicine, 71, 1357-1359. http://dx.doi.org/10.1097/00001888-199612000-00021

Shukr, I., Zainab, R., \& Rana, M. H. (2013). Learning styles of postgraduate and undergraduate medical students. Journal of College of Physicians and Surgeons Pakistan, 23, 25-30.

Tabachnick, B. G., \& Fidell, L. S. (2007). Using multivariate statistics. Upper Saddle River NJ: Pearson Education Inc.

Walley, T., Bligh, J., Orme, M., \& Breckendrige, A. (1994). Clinical pharmacology and therapeutics in undergraduate medical education in the UK: Current status. British Journal of Clinical Pharmacology, 37, 129-135. http://dx.doi.org/10.1111/j.1365-2125.1994.tb04252.x 